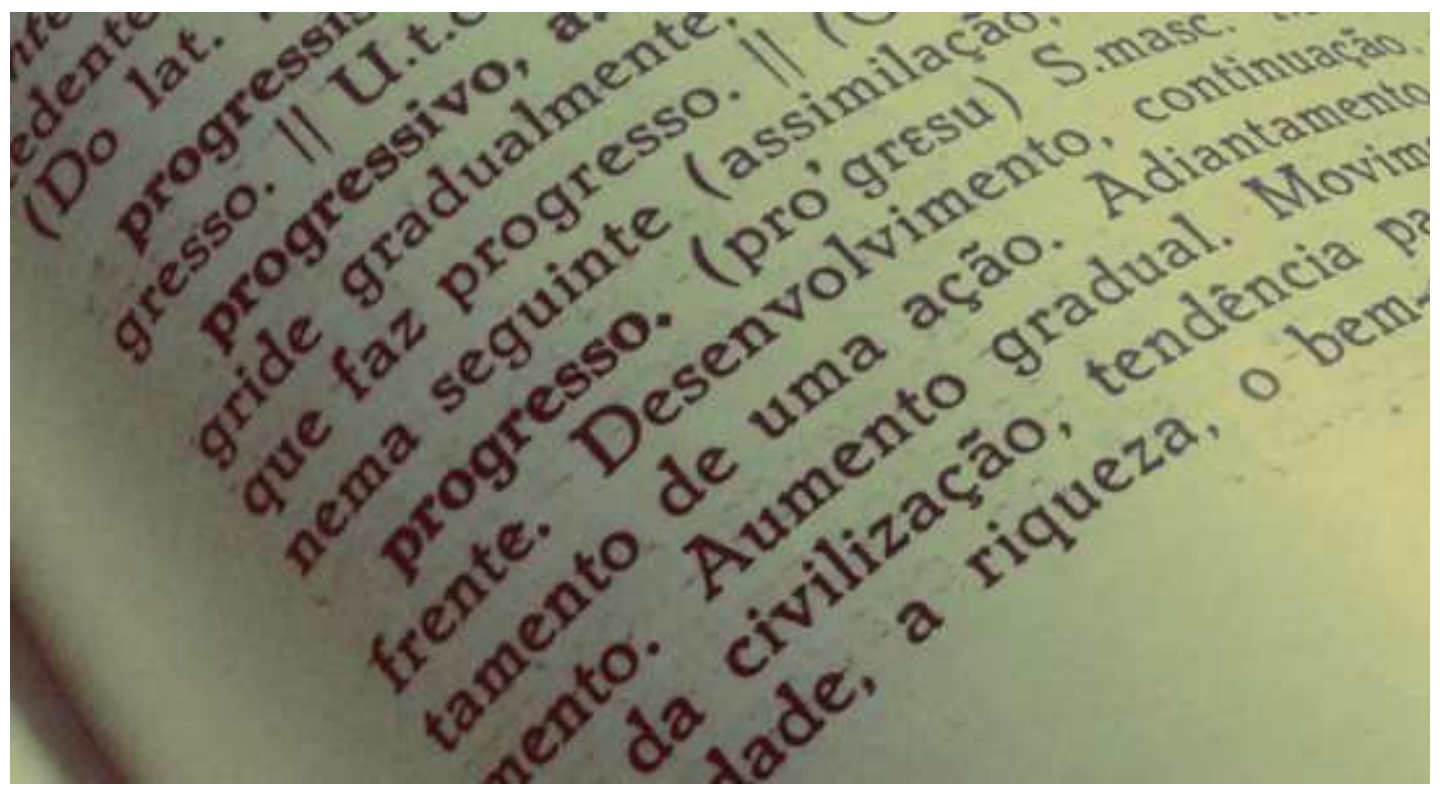

\title{
O “progresso” e a significação da sociedade em alguns dos primeiros dicionários monolíngues brasileiros
}

The "progress" and the significance of society in some of the first monolingual Brazilians dictionaries

\section{Resumo:}

Neste estudo analisamos a palavra progresso e suas cognatas em três dicionários brasileiros publicados por volta de 1938 a 1967. Fundamentamo-nos em dois lugares de reflexão, a História das Ideias Linguísticas e a Semântica do Acontecimento e buscamos compreender a designação dessas palavras observando seus sentidos no acontecimento enunciativo, ao serem determinadas pelas predicações, nas definições lexicográficas, no movimento entre a paráfrase e polissemia.

Palavras-chave: progresso; dicionário; sociedade; acontecimento.

\section{Abstract:}

In this study we analyzed the word progress and its cognates in three Brazilian dictionaries published around 1938 to 1967 . We based in two places of reflection, the History of Linguistics Ideas and the Semantics of Event and we seek to understand the designation of these words watching their senses in the enunciative event, to be determined by the predications, in the lexicographic definitions, in the movement between the paraphrase and polysemy.

Keywords: progress: dictionary; society; event.

\footnotetext{
* Mestre e doutoranda em Linguística pelo Instituto de Estudados da Linguagem (IEL) na Universidade Estadual de Campinas (UNICAMP). Endereço postal Rua Otaviano Viana, 75 - Jardim Santana, Campinas/SP - CEP 13088-676. E-mail: rosiregio@ yahoo.com.br
} 
A preguiça é a mãe do progresso. Se o homem não tivesse preguiça de caminhar, não teria inventado a

roda.

Mário Quintana

\section{Introdução}

Compreender como a palavra progresso significa a sociedade brasileira, em momentos particulares, é uma questão que se coloca para nós há algum tempo. Por isso, temos analisado essa palavra em diferentes materialidades ${ }^{1}$ e em momentos históricos distintos, sempre com o objetivo de entender como progresso se relaciona com o movimento da sociedade e passa a significar um movimento social. No estudo apresentado neste texto observamos como a palavra progresso significava no momento em que o país fixava suas raízes como nação independente, momento em que ocorrem "de par com a crise da cafeicultura, os surtos de industrialização, a urbanização" (IANNI, 2004, p. 25) e que, conforme Ianni (idem, p. 16) "preconizavam a modernização, naquele tempo denominada progresso".

Pesquisando o verbete progresso no Dicionário Etimológico Resumido, de Antenor Nascentes (1966), observamos que ele está apresentado da seguinte forma: "Progresso. Do lat. progressu "marcha para a frente", por via erudita", ou seja, esta palavra teve origem no Latim e significava "marcha para a frente", apontando um sentido de movimento cadenciado e em uma direção definida. O sentido de movimento adiante presente nesta acepção não deixou de determinar a palavra, mas hoje progresso apresenta uma diversidade de acepções determinando-a e atribuindo a ela novos e diferentes sentidos. Por essa observação podemos mostrar que as palavras não mantêm sempre a mesma significação. Desse modo, interessa-nos analisar os sentidos da palavra progresso e suas cognatas em alguns dicionários da Língua Portuguesa e, com isso, compreendermos como elas mudam de sentido nas relações que estabelecem com a sociedade. Essas alterações podem ser observadas nas palavras a partir das determinações que são relações que se dão ao longo da história.

\footnotetext{
${ }^{1}$ Essas análises podem ser observadas em Oliveira (2007, 2009, 2009a). 
Neste estudo analisamos os sentidos da palavra progresso e suas cognatas no Pequeno Dicionário Brasileiro da Língua Portuguesa (1938 a 1967²), organizado por Hildebrando Lima e Gustavo Barroso ${ }^{3}$. Após analisarmos as edições deste dicionário, observamos as possíveis relações entre os sentidos presentes nele e em outros dois dicionários brasileiros: Grande e Novíssimo Dicionário da Língua Portuguesa (1942$43^{4}$ ), organizado por Laudelino Freire e Dicionário da Língua Portuguêsa da Academia Brasileira de Letras $\left(1966^{5}\right)$, organizado por Antenor Nascentes.

A análise do sentido das palavras propostas, em dicionários brasileiros ${ }^{6}$, interessa-nos à medida que consideramos os dicionários, assim como as gramáticas, como instrumentos de gramatização (AUROUX, 1992) e de regulação de uma língua (ELIAS DE OLIVEIRA, 2006) e também porque, conforme Orlandi (2002, p. 103), "há um processo pelo qual o dicionário, ao representar a língua a provê de realidade", o efeito envolvido nesse processo é o de que o dicionário representa o lugar da completude da língua, da sua unidade. Desse modo, podemos observar a história do país

\footnotetext{
${ }^{2}$ As edições analisadas foram da primeira à décima primeira, à isenção da quarta, sétima e oitava, que não foram encontradas.

${ }^{3}$ O Pequeno Dicionário tem como primeiros organizadores Hildebrando Lima e Gustavo Barroso e recebe participação de outros grandes nomes da lexicografia brasileira. Com exceção da primeira edição que não traz dados catalográficos na primeira página, a segunda edição consta como "revisto por Manuel Bandeira e José Baptista da Luz" e "revista e aumentada por Antenor Nascentes"; na terceira edição, está "revisto por Manuel Bandeira e José Baptista da Luz" e "refundida, revista e aumentada por Antenor Nascentes (Vocabulário de Filologia e Gramática); Aurélio Buarque de Hollanda Ferreira (Brasileirismos e redação)" e outros; a sexta e nona edições constam "revisto na parte geral por Manuel Bandeira e José Baptista da Luz" e "inteiramente revista e consideravelmente aumentada - sobretudo na parte de brasileirismos - por Aurélio Buarque de Hollanda Ferreira. Este dicionário foi refundido e aumentado a partir da $2^{\mathrm{a}}$ edição por Antenor Nascentes (Filologia e Gramática), [...] da $3^{\mathrm{a}}$ à $5^{\mathrm{a}}$, por Aurélio Buarque de Hollanda Ferreira (Brasileirismos e redação)" e outros; na décima primeira edição não consta os nomes dos organizadores e tem como destaque "supervisionado e consideravelmente aumentado por Aurélio Buarque de Hollanda Ferreira com a assistência de José Baptista da Luz e revisto e aumentado por

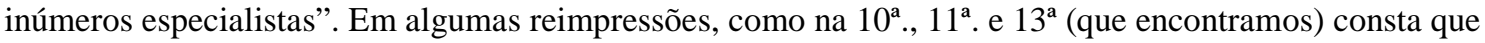
esse dicionário foi "supervisionado e consideravelmente aumentado até a 10a . edição por Aurélio Buarque de Hollanda Ferreira com a assistência de José Baptista da Luz e revisto e aumentado por inúmeros especialistas". Traz ainda, na página seguinte, a informação: "este dicionário - aumentado em cerca de $25 \%$ na décima edição - foi organizado por Hildebrando de Lima, com revisão, na parte geral, por Manuel Bandeira e José Baptista da Luz; refundido e aumentado, na 2a . edição, por Antenor Nascentes (Filologia e Gramática)", constam também os nomes de muitos outros colaboradores que foram sendo acrescentados a cada edição, cada um em sua devida área.

${ }^{4} \mathrm{O}$ volume 1 desse dicionário foi lançado em 1939, mas o volume 4, em que estão as palavras que analisamos, foi publicado entre 1942 - 1943.

${ }^{5}$ Esse dicionário foi elaborado entre 1941 e 1943, mas foi publicado entre 1964 e 1967. As palavras que analisamos estão no seu $3^{\circ}$ Tomo, publicado em 1966.

${ }^{6}$ Os dicionários que analisamos foram publicados por volta de 1938 a 1967.
} 
"pela história de constituição da língua e do conhecimento a respeito dela" (ORLANDI, ibidem, p. 9).

Ainda no que se refere ao dicionário como lugar de observação dos sentidos Elias de Oliveira (2006, p. 18), retomando Auroux (1992), diz que "ao descrever as línguas, os dicionários (e as gramáticas) produzem um prolongamento do saber linguístico do falante, que não apenas o estende, mas o transforma”. Segundo a autora, essa transformação do saber linguístico do falante pelos dicionários é política, pois produz a afirmação de um saber com efeito de normatividade sobre a língua e estabelece as possibilidades de pertencimento daqueles que dominam essa língua e de exclusão dos que não a dominam. Conforme Guimarães (2002, p. 17), enunciar é uma prática política na medida em que o político é a contradição que instala o conflito no centro do dizer, "ele se constitui pela contradição entre a normatividade das instituições sociais que organizam desigualmente o real e a afirmação de pertencimento dos não incluídos".

Os dicionários selecionados fazem parte da história da lexicografia brasileira ${ }^{7}$. Eles foram produzidos no século posterior à independência do Estado brasileiro, em um momento de produção em que se objetivava legitimar a língua nacional e, desse modo, marcar o lugar da nação brasileira enquanto independente.

O momento, por volta das décadas de 1930 e 1940, em que esses dicionários foram produzidos, é marcado por muitos embates, propostas e transformações no Estado brasileiro, em que ocorre a consolidação da República Nova no Brasil. Entre outros movimentos sociopolíticos, tem destaque nesse momento a "marcha para o Oeste", que foi uma proposta do governo Getúlio Vargas por volta de 1939, e tinha como objetivo a ““"ocupação” das terras do Centro-Oeste do Brasil" ". Essa proposta tem grande ênfase na enunciação do Estado e ganha destaque na imprensa brasileira, especialmente na matogrossense. Esses discursos enfatizam que a "marcha para o Oeste" é uma forma de progresso para o país. De acordo com essa proposta, o país precisa progredir ocupando seus próprios espaços em um movimento de "colonização" das regiões mais afastadas, especialmente do Oeste.

\footnotetext{
${ }^{7}$ O Pequeno Dicionário Brasileiro da Língua Portuguesa é considerado o primeiro monolíngue brasileiro (1938), seguido pelo Grande e Novíssimo Dicionário da Língua Portuguesa, organizado por Laudelino Freire (1939); o Dicionário da Língua Portuguêsa da Academia Brasileira de Letras, organizado por Antenor Nascentes (1964-1967), tem sua importância especialmente por ser atribuído à Academia Brasileira de Letras.

${ }^{8}$ Essa questão pode ser melhor compreendida em Oliveira (2007).
} 
No trecho a seguir, retirado do Jornal O Estado de Mato Grosso, de um texto publicado em 1940, e escrito por Ildefonso Escobar (do Conselho Nacional de Geografia), pode ser observada a palavra progresso na relação com a "marcha para o

Oeste": "a marcha para o Oeste, terá a Inestimável vantagem de atender a uma necessidade política, econômica e social (...) será a propulsora de formidável progresso comum". Pelas relações de determinação semântica aí postas, a "marcha para o Oeste" é determinada por progresso, sendo que há para o Brasil e para o continente sulamericano a possibilidade de um "formidável progresso comum", mas somente a partir da realização da marcha para o Oeste que, pelas relações apresentadas no texto analisado, possibilitará a civilização dos selvagens e, somente assim, produzirá o progresso. Nessas relações, um dos maiores argumentos para a realização da marcha para o Oeste é o progresso.

\section{A Semântica do Acontecimento}

Para o desenvolvimento de nossas análises, mobilizamos a Semântica do Acontecimento, conforme proposta no Brasil por Guimarães. Nesta teoria, as palavras ou "expressões linguísticas significam no enunciado pela relação que têm com o acontecimento em que funcionam”, com o texto (GUIMARÃES, 2002, p. 5). Nessa medida, a enunciação se dá pelo funcionamento da língua, enquanto acontecimento de linguagem. Acontecimento que funciona porque o seu presente projeta em si mesmo um futuro e, por outro lado, tem um passado enquanto memorável, que o faz significar. É na enunciação enquanto acontecimento de linguagem que investigamos os sentidos da palavra progresso e de suas cognatas em alguns dicionários monolíngues brasileiros. Desse modo, tomamos o passado não enquanto lembrança (individual), mas enquanto rememoração de enunciações, e consideramos na constituição do acontecimento a sua temporalidade e ainda o real enquanto materialidade histórica.

Nesse sentido, consideramos o texto, tal como conceituado por Guimarães (2011, p. 9), como "uma unidade de significação" e caracterizando-o "não como composto por segmentos, mas como integrado por elementos linguísticos de diferentes níveis e que significam em virtude de integrarem esta unidade. O sentido dos enunciados é esta relação de integração" (ibidem, p. 22-23). Conforme esse autor, a relação de integração é constituída na enunciação, e, caso haja alguma distância entre os 
elementos linguísticos, ela será preenchida a partir de um falante/locutor que "se instalaria" entre os elementos linguísticos.

Trabalhando sobre a temporalidade do acontecimento enunciativo do dicionário, observamos como a palavra progresso e suas cognatas são definidas nos dicionários tomados como textos e compostos por "unidades textuais menores: o prefácio, a apresentação, as tabelas explicativas, etc. Dentre essas unidades, estão os verbetes" (ELIAS DE OLIVEIRA, 2006, p. 37). Os verbetes, que são compostos por palavraentrada e definição, são o objeto de análise deste artigo. A definição é tudo o que predica a palavra-entrada, tudo o que se diz sobre ela. Conforme Elias de Oliveira (idem, p. 37) a definição é constituída por "predicados de tipos diferentes (acepções, exemplos, etimologia, regência/colocação, representação fonética, etc.)". Para nossas análises elegemos especialmente as definições e os exemplos.

Tal como Elias de Oliveira (2012, p. 1) "consideramos o saber produzido sobre uma palavra no dicionário como parte da história da palavra, à medida que integra sua história de enunciações". Desse modo, buscamos compreender na enunciação do dicionário a designação da palavra progresso e suas cognatas tendo em vista as relações parafrásticas e polissêmicas existentes entre as palavras-entrada e as definições presentes nos verbetes dos diferentes dicionários, no conjunto de edições analisadas. Conforme Guimarães (2002; 2004a; 2006), a designação é a significação de um nome remetida ao real e enquanto uma relação com outros nomes tomada na história, sendo, portanto, linguística e histórica. Compreender a designação é dizer as relações estabelecidas entre as palavras em um acontecimento de linguagem.

Para estabelecer a designação das palavras propostas, analisamos como as palavras-entrada são determinadas pelas predicações, nas definições lexicográficas, no movimento entre a paráfrase e a polissemia ${ }^{9}$. Sendo a polissemia tomada a partir da concepção da Análise do Discurso como um processo fundamental da linguagem de deslocamento dos sentidos, já que se assume que o sentido sempre pode vir a ser outro, pois o funcionamento da língua ocorre no equívoco. Conforme Orlandi (2000, p. 36), a linguagem funciona na tensão entre a paráfrase e a polissemia, nesse sentido, "os processos parafrásticos são aqueles pelos quais em todo dizer há sempre algo que se

\footnotetext{
9 Tal como também, a partir da perspectiva da Semântica do Acontecimento, analisa as palavras “cidadania", "cidadão" e outras relacionadas, Elias de Oliveira (2004 e 2006).
} 
mantém, isto é, o dizível, a memória. [...] Ao passo que, na polissemia, o que temos é deslocamento, ruptura de processos de significação. Ela joga com o equívoco”.

Interessa-nos compreender nesses dicionários monolíngues brasileiros como o sentido de uma palavra pode ser parafrástico e ser polissêmico, repetir e deslocar. Pensar este movimento contraditório traz para a análise, por exemplo, a possibilidade de compreender como a sociedade brasileira se significa na relação entre o progresso como movimento favorável, transformação positiva, ou como transformação negativa, ou ainda como continuação.

\section{O Pequeno Dicionário Brasileiro da Língua Portuguesa \\ O Pequeno Dicionário - primeira e segunda edições $(1938$ - 1939¹)}

A primeira publicação desse dicionário apresenta seis palavras-entrada com a raiz de progresso. São elas: progredimento, progredir, progressão, progressista, progressivo e progresso. A primeira palavra, em ordem alfabética, é progredimento. Essa palavra tem como acepção "ato ou efeito de progredir", logo progredimento remete a progredir.

A palavra progredir, que vem na sequência, apresenta como acepções "caminhar para diante", "avançar", "desenvolver-se", "ir aumentando". Nesse conjunto é possível perceber um movimento em sentido favorável e também um sentido de movimento espacial que indica uma direção definida, "para diante".

Em seguida está a palavra progressão que tem como acepções: "progredimento"; "continuação"; e uma terceira relacionada à Matemática, definindo "série de números ou têrmos entre cada um dos quais e o antecedente há uma razão constante". Ao ser posta como sinonímia de progredimento, a palavra progressão, em uma das suas acepções passa a apresentar os sentidos contidos nas relações do termo que a determina. Nesse caso, o que determina progredimento determina também progressão. Então progressão traz como acepção "ato ou efeito de progredir" e, por conseguinte, o que progredir significa: uma direção favorável ao desenvolvimento.

\footnotetext{
${ }^{10} \mathrm{Na}$ segunda edição, de 1939, as definições apresentadas para todas as palavras analisadas permanecem sem nenhuma alteração, ocorre somente uma mudança na passagem da indicação de classe gramatical que na primeira edição que é de 1938, era "n.m." (nome masculino) e na de 1939 é "s.m." (substantivo masculino).
} 
Por outro lado, ao ser definida também como "continuação" a palavra progressão apresenta um movimento em duas direções, pois aponta tanto para o sentido de movimento adiante, de desenvolvimento, como indica um sentido em direção ao que se mantém, à permanência, manutenção. Quanto à acepção relacionada à Matemática, há um sentido de constância que aponta para a permanência e a continuidade. Essa duplicidade de sentidos apresentada para progressão indicam um movimento polissêmico em direções opostas na determinação dessa palavra.

$\mathrm{Na}$ sequência está a palavra progressista. Ela traz as seguintes acepções: "partidário do progresso"; "que é favorável ao progresso". Nesse caso os enunciados definidores indicam um sujeito que sustenta uma posição, partilha dos ideais do progresso, pois é partidário dele ou favorável a ele. Esse verbete dá visibilidade a um conflito em relação à perspectiva de progresso, que pode não ser defendida por todos. Pela determinação de progresso sobre progressista, as relações que definem progresso definem também progressista. É interessante observar que "favorável" é uma qualificação posta também para o que define progresso, como pode ser visto logo adiante.

O verbete progresso tem como acepções: "movimento ou marcha para a frente", “desenvolvimento", “aumento", "adiantamento em sentido favorável”. Essas acepções apresentam uma relação parafrástica com as acepções de progredir. Por exemplo: progredir é: "caminhar para diante"; "avançar"; "desenvolver-se"; "ir aumentando" e progresso é: "movimento ou marcha para a frente"; "desenvolvimento"; "aumento"; “adiantamento em sentido favorável”. Elas produzem um sentido de evolução favorável. As outras acepções apresentadas em progredir e progresso são correlatas (variam apenas de categoria gramatical), com exceção de "avançar" que sendo acepção de progredir não tem uma correlata em progresso.

Antes de progresso, o dicionário traz o verbete progressivo. Esse verbete, assim como progressão, também apresenta o movimento polissêmico bidirecional, pois é possível observar sentidos que apontam duas direções distintas. Sendo apresentado para progressivo um conjunto de acepções da seguinte forma: "que progride"; "que muda de lugar, andando"; "que segue uma progressão"; "que se vai realizando gradualmente". As acepções "que progride" e "que muda de lugar, andando", produzem um sentido de movimento. Já nas acepções seguintes "que segue uma progressão"; "que se vai 
realizando gradualmente" é evidenciada uma relação com uma das acepções por sinonímia de progressão, "continuação" indicando um sentido de permanência.

Nessas edições, as palavras progresso e progredir são palavras-eixo do conjunto de definições dos verbetes analisados, porque elas determinam as outras palavras; são as palavras em torno das quais todas as outras significam. Neste momento a palavra-base ${ }^{11}$ é progredir, pois a maioria das palavras analisadas se concentra em torno dela.

\section{O Pequeno Dicionário - terceira e quinta edições (1942 - 1944)}

A terceira edição apresenta alterações, em relação às edições anteriores, que incidem sobre as entradas progredir e progresso, palavras-eixo do conjunto de verbetes. Essas alterações permanecem na sexta, nona, décima e décima primeira edições.

Em relação à palavra progredir, além de permanecerem as acepções observadas anteriormente, são acrescentadas as seguintes: "fazer progresso", "evolver", "adiantarse". Essas acepções mantêm relações de sentido com as apresentadas nas edições anteriores, por isso, reforçam os sentidos em direção a "movimento" a "adiantamento em sentido favorável". Além das definições que foram acrescentadas a progredir, há também a inserção da marcação "rel." (relativo) que indica que as acepções anteriores a ela podem ser sintetizadas pelas que a seguem: "desenvolver-se" e "adiantar-se"

Nesta edição a relação de força entre as palavras-eixo progredir e progresso se reconfigura e progresso passa a ser a palavra-base. A observação das alterações ocorridas no verbete progresso possibilita compreender essa reconfiguração que é estabelecida com a inserção das seguintes acepções: “(sociol.) acumulação de aquisições materiais e de conhecimentos objetivos no quadro de uma cultura"; "fenômeno que tem como condição as transformações da vida social, e consiste num aumento de significado e alcance da experiência humana". Antes dessas acepções há a marcação "sociol." que se refere às duas acepções e indica que elas estão relacionadas ao quadro de estudos sociológicos. Progresso passa então a significar como termo de uma disciplina e, nesse sentido, torna mais evidente sua relação com o movimento da

\footnotetext{
${ }^{11}$ Utilizamos o termo palavra-base para indicar a palavra central nas relações de determinação. Aquela que determina o maior número de palavras.

${ }^{12}$ Os dicionários atuais, normalmente apresentam uma indicação numérica para separar os conjuntos de acepções ficando claros os domínios onde começa e onde termina uma e outra, o que define a relação da marcação com as acepções, isso não acontece no Pequeno Dicionário da Língua Portuguesa. O que observamos é que as marcações projetam para frente, por isso, a partir do aparecimento do marcador, todas as acepções que surgem estão relacionadas a ele.
} 
sociedade tal como interpretado no quadro de uma disciplina de análise social. As "transformações da vida social" indicadas apontam para aquisições materiais e culturais. Essa é a primeira vez em que está havendo uma remissão ao social e à própria ciência do social. Essa remissão é de grande importância para nossa análise, pois traz sentidos diretamente relacionados à nossa proposta de observar como as palavras significam a sociedade de maneira ampla e generalizada.

Esse acréscimo marcado como relativo à Sociologia reforça os sentidos de "adiantamento em sentido favorável", e de "movimento", e evidencia um novo sentido para progresso que passa a apresentar uma relação sociológica que indica acumulação e também mudança. Desse modo, é estabelecida uma ambiguidade na determinação de progresso, pois a caracterização social estabelecida reforça o sentido de mudança, inclusive pelo aparecimento de "transformações da vida social", mas estabelece um sentido de continuação em direção ao que vai ser aumentado, acumulado: "conhecimentos objetivos", "o significado e alcance da experiência humana". O que pode ser tomado como acumulação, aponta o sentido de continuação.

Essas definições apontam uma polissemia para o verbete que tem como palavrachave progresso, pois elas mantêm os sentidos evidenciados nas edições anteriores, de "movimento" e "adiantamento em sentido favorável", e acrescentam para progresso o sentido de "continuação". Essas novas relações produzem uma divisão de sentidos para o verbete. Nessa divisão é evidenciado um novo modo de dizer para progresso na relação com a sociedade, relação que agora os identifica e aproxima.

Nessas relações ocorre uma reconfiguração das palavras-eixo em que, pela direção da determinação, progresso se torna a palavra-base; ao passar a determinar progredir, determina também progressivo e progredimento. Isso parece indicar que está havendo uma inversão da prioridade enunciativa dessas palavras, em que progresso passa a ter os sentidos mais estáveis e/ou de maior circulação.

Essas determinações de progresso indicam novos sentidos para esse verbete, que passa a apresentar também um sentido de "acumulação" que aponta para a "continuação", mas que não interfere na direção das outras determinações, que continuam produzindo o sentido de "adiantamento em sentido favorável", observado desde o início das análises. A inserção de "transformações da vida social" intensifica o movimento em direção a esse sentido. 
Já a quinta edição traz como alteração apenas a acepção relacionada à matemática de forma que apresenta os tipos de sequência numérica - aritmética e geométrica - diferenciando-as e esclarecendo que a razão é constante, mas como resultado de subtração ou divisão. Desse modo o sentido de constante se mantém, mas apontando para baixo, para um número que será menor.

\section{O Pequeno Dicionário - sexta edição (1946)}

A primeira alteração que ocorre nesta edição não está diretamente relacionada às acepções, mas a um elemento morfológico no corpo definicional. Trata-se da palavra progredir, que recebe a classificação verbal "Irregular. Conjuga-se como o verbo agredir".

Ocorre alteração também em progressista: "progressista, adj. e s. m. e f. Que, ou pessoa que é favorável ao progresso; partidário do progresso". Nesse verbete a classificação morfológica deixa de ser somente como adjetivo (adj.) e passa a haver uma classificação também como substantivo masculino e feminino ( $s$. m. e $f$ ). Desse modo, a palavra progressista assume duas categorias gramaticais, o que demonstra que seu emprego está se dividindo de modo que a língua apresenta outras possibilidades de sintagmatização, o que é acrescido ainda da duplicação do gênero, pelo qual se atribui à mulher um pensamento ou posição em relação à sociedade. Indicar a existência de dois gêneros para a palavra é indicar que homem e mulher podem ser progressistas, logo, que ambos têm participação nos processos sociopolíticos. As alterações morfológicas de classe e gênero em progressista indicam a produtividade da palavra na sociedade.

Ao ser inserida a classificação morfológica como substantivo, o sujeito verbal do enunciado definidor deixa de ser elíptico e passa a ser marcado por "pessoa", o que reforça a possibilidade de dois gêneros: "Que, ou pessoa que é favorável ao progresso". Ocorre ainda uma inversão em que "partidário do progresso" nas outras edições aparecia como primeiro enunciado definidor e nesta passa a ser o segundo. Com esta inversão, o que é "favorável" ganha destaque, pois passa a ocupar a primeira posição, e, mesmo não qualificando diretamente o progresso, o que é "favorável" é colocado na relação com ele. 


\section{O Pequeno Dicionário - nona, décima e décima primeira edições (1951 - 1963 - $1968^{13}$ )}

Na nona edição, a alteração morfológica realizada em progressista, na edição anterior, se mantém, mas reformulada: adjetivo de 2 gêneros e substantivo de 2 gêneros. Ainda no verbete de entrada progressista é acrescentado um enunciado definidor relacionado à política brasileira, em que progressista é, no Brasil, "partidário da Regência do Padre Feijó", pois está com a marcação "Bras." que significa Brasil. Esse enunciado introduz um memorável político e nos diz que o sentido de ser progressista no Brasil está atrelado aos sentidos produzidos ainda durante o período regencial, e relacionado aos princípios do positivismo ${ }^{14}$ desenvolvido por Augusto Comte e seguido por Padre Feijó, regente entre 1835 e 1837. O memorável da política brasileira do século XIX, aqui trazido, inscreve um passado para o caráter progressista na história política brasileira. Esse memorável ao individualizar a sociedade, produz uma relação polissêmica para progressista que apresenta dois sentidos: um que corresponde à sociedade em geral e é produzido nas acepções "que, ou pessoa que é favorável ao progresso", "partidário do progresso"; e outro sentido relacionado especificamente a um período preciso da sociedade brasileira, produzido na definição "partidário da Regência do Padre Feijó", acompanhada da marcação "Bras".

Nesta mesma edição, a palavra progressivo recebe uma marcação de domínio de especialidade ligada à medicina: “(Med.) (V. Paralisia)". Este verbete passa a produzir um sentido negativo por ser marcado com a alusão a uma doença ${ }^{15}$, a paralisia. Esta doença envolve a perda dos movimentos, a possibilidade de evolução em direção ao "não movimento", à "paralisação" - paralisar gradativamente, progressivamente. Essa

\footnotetext{
${ }^{13}$ A décima edição (1963) e a décima primeira (1968) não apresentam nenhuma alteração.

${ }^{14}$ Em relação ao positivismo no Brasil, Orlandi (1997) comenta que o enunciado "Ordem e Progresso" utilizado como dístico na Bandeira Nacional "resume, de certo modo, a simbologia positivista no Brasil. [...] Esse enunciado se inscreve no discurso da República, tendo sido formulado na época de sua implantação no Brasil, fazendo assim parte das relações de força e de sentidos que aqui então se delineavam" (p.10). A autora traz alguns dos deveres positivos e negativos prescritos pela Sociedade Positivista do Rio de Janeiro: "1. Não possuir escravos; 2. Não aceitar cargos políticos (durante a fase de transição); 3. Não aceitar funções acadêmicas; 4. Não participar do jornalismo; 5. Assinar o nome em suas publicações e assumir sua responsabilidade moral e legal." (p.14).

${ }^{15}$ Esse sentido de doença aparece nos dicionários brasileiros somente em 1951, mas ele já estava disponível na língua portuguesa, pois o "Diccionário da Língua Portugueza", de Antonio de Moraes Silva na edição de 1813, já apresentava esse sentido que vinha como enunciado definidor de progressivo, da seguinte forma: "doença progressiva; que não mata do primeiro ataque ou golpe".
} 
marcação reforça o sentido das acepções "que progride"; "que segue uma progressão"; "que se vai realizando gradualmente", que são apresentadas desde a primeira edição e produzem um sentido de movimento favorável. Ao contrário do sentido evidenciado nas acepções, a marcação “(Med.) (V. Paralisia)” aponta uma direção negativa, desfavorável.

A oposição observada acima evidencia um paradoxo, pois aponta, ao mesmo tempo, um movimento progressivo na paralisia que é a perda dos movimentos, progressiva. Os dois movimentos são graduais, porém, enquanto as acepções "que progride"; "que segue uma progressão"; "que se vai realizando gradualmente" indicam um sentido de acréscimo, de movimento, e, mesmo relacionado à permanência, à constância, como é o caso da matemática, aponta para o favorável; enquanto a marcação “(Med.) (V. Paralisia)” indica sentido de perda de movimentos, que leva à paralisação, apontando para o desfavorável.

É apresentado, então, o sentido de "paralisia", a progressão de uma doença que provoca a perda dos movimentos. Ou seja, um movimento contrário ao que o progresso proporciona; um movimento progressivo que produz um retrocesso. Essas relações apontam um sentido negativo para progressivo, que não determina outros verbetes, desse modo, esse sentido se restringe a esta palavra e ao domínio específico da medicina. A inserção desta marcação, ao trazer para o verbete progressivo um sentido que aponta para a paralisação, produz mais um movimento polissêmico, pois os sentidos das acepções nas edições anteriores apontavam para a mudança, para o desenvolvimento e para a continuação.

O movimento de sentidos observado nesta edição reflete um presente para as cognatas de progresso em que se inscreve uma relação com a medicina, marcado pela paralisia e um passado evidenciado pelo memorável da política brasileira do século XIX, na relação com os ideais do Padre Feijó e do Partido Liberal. Nesta relação, esse conjunto de palavras (progresso e suas cognatas) nos mostra que se há um presente que determina o progresso há também um passado que afeta o seu sentido.

Em algumas edições desse dicionário os verbetes apresentam alterações. Elas sempre reforçam o sentido de progresso enquanto mudança, movimento, "adiantamento em sentido favorável" e mantêm a dupla direção da polissemia na relação com o sentido de "continuação" enquanto permanência e desenvolvimento. Esses sentidos favoráveis para progresso e suas cognatas são mantidos, no Pequeno Dicionário Brasileiro da Língua Portuguesa, por muito tempo, desde a primeira edição em 1939, vindo a 
aparecer um sentido negativo somente a partir de 1951, quando surge a marcação “(Med.) (V. Paralisia)" determinando o sentido de progressivo. A inclusão dessa marcação negativa para progressista não afeta o sentido positivo ${ }^{16}$ que determina 0 progresso, desse modo, essa palavra eclode, na sociedade brasileira, com esse sentido de que o progresso é algo muito bom para a sociedade, sentido que permanece nas edições analisadas no Pequeno Dicionário.

\section{O progresso favorável}

Nas relações analisadas, o sentido para progresso e suas cognatas é regularmente favorável, mas observamos que os sentidos dessas palavras, no Brasil, produzem uma relação ambígua, estando ora como movimento, mudança, "adiantamento em sentido favorável", ora como permanência, continuidade que também são afetados por desenvolvimento. Além disso, as palavras analisadas aparecem, antes da nona edição, sempre indicando um sentido favorável. Isso ocorre sem que sejam apresentados elementos de contradição, como a doença que progride, e que vai surgir nesse dicionário somente na nona edição, mesmo com esse elemento já estando disponível na língua portuguesa, como pode ser observado mais acima em Moraes.

Na sequência observaremos no Grande e Novíssimo Dicionário da Língua Portuguesa e no Dicionário da Língua Portuguêsa da Academia Brasileira de Letras se esses sentidos analisados no Pequeno Dicionário Brasileiro da Língua Portuguesa são evidenciados nesses outros dicionários, se as relações observadas, de alguma forma, são reforçadas ou se novos sentidos são evidenciados.

\section{Grande e Novíssimo Dicionário da Língua Portuguesa (1942-43)}

Nesse dicionário observamos a apresentação de oito palavras-entrada entre progresso e outras com a mesma raiz. Duas dessas palavras não constam no Pequeno Dicionário Brasileiro da Língua Portuguesa ${ }^{17}$ (PDBLP): progressismo e

\footnotetext{
${ }^{16}$ Entendemos positivo no sentido de favorável, não no sentido positivista.

${ }^{17}$ Como os nomes dos dicionários serão repetidos algumas vezes achamos abreviar seus nomes. Desse modo, nos referiremos ao Pequeno Dicionário Brasileiro da Língua Portuguesa como PDBLP; ao Grande e Novíssimo Dicionário da Língua Portuguesa como GNDLP; e ao Dicionário da Língua Portuguêsa da Academia Brasileira de Letras, que analisaremos mais adiante, como DLP.
} 
progressivamente. Quanto às que se repetem, algumas apresentam diferentes acepções. Vejamos essas diferenças.

O Grande e Novíssimo Dicionário da Língua Portuguesa (GNDLP) não traz diferenças nas acepções do verbete progredir, em relação ao PDBLP, mas são apresentados alguns exemplos relacionados às acepções desse verbete. Isso é uma diferença no modo de textualização do verbete em relação ao PDBLP, que não traz exemplos. Sendo que eles podem funcionar afetando as acepções de alguma forma, seja reforçando-as, especificando-as ou mesmo alterando seus sentidos. No caso observado nesse dicionário os exemplos reforçam o sentido das acepções.

Uma possibilidade de reforço dos exemplos está nas relações estabelecidas para progredir no PDBLP, que produzem uma paráfrase apontando um sentido, sempre favorável, de movimento, de "adiantamento em sentido favorável”.

Nesse dicionário, a palavra progressão tem como acepções "desenvolvimento progressivo"; "progresso"; "continuação", "sucessão"; "marcha ou movimento para diante"; "Mat. Série de números que derivam sucessivamente uns dos outros segundo uma mesma lei". O verbete progressão apresenta ainda uma divisão em "subverbetes ${ }^{18,}$ mostrando os diferentes tipos possíveis de progressão na ciência matemática. Ao estabelecer esta divisão, esses desdobramentos da palavra-entrada deveriam funcionar como uma relação homonímica, quando na verdade é apontado um novo sentido para progressão matemática que passa a significar, também, um aumento ou uma diminuição de "termos", independente de ter uma constância.

Essas acepções apontam para progressão sentidos de movimento, de “desenvolvimento", que são reforçados nesse dicionário pela determinação de progresso que não aparece no PDBLP. Há também um sentido de "continuação" determinando progressão, mas a divisão numérica separando as acepções em conjuntos de acordo com a significação que as diferencia de forma a desfazer a ambiguidade presente no PDBLP, em que não fica claro se "progredimento" e "continuação" são acepções que apresentam significações diferentes ou compreendem um mesmo sentido. Essas diferenças, aliadas à divisão de progressão em subverbetes, fazem com que, neste domínio seja reforçado para progressão o sentido de movimento, de desenvolvimento.

\footnotetext{
${ }^{18}$ Utilizo este termo para me referir à divisão realizada no verbete progressão em que são apresentados os tipos de progressão: progressão aritmética, progressão ascendente, progressão descendente, progressão geométrica, progressão por diferença, progressão por quociente e suas acepções.
} 
Nesse dicionário a divisão numérica entre as acepções aponta para "continuação" a mesma significação que "sucessão", desse modo, essas palavras produzem um sentido de sequência, segmento, que podem estar relacionadas a movimento. Nas relações de determinação com progresso, "continuação" está na mesma acepção que "desenvolvimento", desse modo, essas palavras produzem a mesma significação: de "desenvolvimento", "acrescentamento". Nessas relações, não é retomado o sentido polissêmico bidirecional apresentado para esse verbete no PDBLP.

Esse dicionário traz como próxima palavra-entrada progressismo, essa palavra não consta no PDBLP. No GNDLP ela tem como acepção "tendência progressista", desse modo, está determinada diretamente por progressista. A palavra "tendência" imprime para "progressista" tanto uma característica própria à natureza individual de pessoas como uma direção que pode ser escolhida em relação ao progresso. Neste caso, há uma relação polissêmica afetando os sentidos desse verbete que aponta tanto para uma característica pré-determinada como para uma escolha de cada indivíduo.

A definição da palavra progressista traz algumas diferenças em relação ao PDBLP. Uma delas é a classificação morfológica que, naquele dicionário, assume a possibilidade de ser adjetivo ou substantivo de 2 gêneros, enquanto no GNDLP progressista é classificado somente como adjetivo ou substantivo masculino. Desse modo, enquanto o PDBLP aponta duas categorias de sujeitos sociais (feminino e masculino) e com possibilidade de participação nos processos sociopolíticos, o GNDLP não explicita essa possibilidade, assumindo um discurso mais conservador.

Outra diferença, em relação à palavra progressista, está nas acepções "diz-se de um partido político em Portugal" e "Membro de um partido político, que em Portugal se denominou progressista" que não aparecem no PDBLP. As acepções apresentadas para progressista, nesse dicionário, assim como as do PDBLP, apontam duas direções de sentidos, sendo que um conjunto de acepções traz um sentido relacionado à sociedade em geral ("Relativo ao progresso ou a progressistas"; "Partidário do progresso"; "que é favorável ao progresso"; "Partidário das ideias do progresso"), mas há um subverbete que apresenta outro conjunto de sentidos específicos para a sociedade portuguesa ("Dizse de um partido político em Portugal"; "Membro de um partido político, que em Portugal se denominou progressista"), particularizando tanto o partido como a sociedade progressista. 
Ao ser particularizado um sentido para a sociedade portuguesa e outro para a sociedade em geral é evidenciada uma polissemia para progressista. Nesta medida a sociedade portuguesa apresenta certos sentidos que a distingue das demais, e é ela que é rememorada como parte da história da palavra. Assim como o PDBLP, no verbete progressista, evidencia sentidos que distinguem a sociedade brasileira das demais, esse dicionário, ao evidenciar um lugar de referência a Portugal, possibilita compreender que, mesmo havendo no Brasil a reivindicação por uma língua nacional ${ }^{19}$, por um espaço social, cultural e político brasileiro, esse dicionário traz para seus sentidos a relação com o colonizador, significando a língua do Brasil e a de Portugal pela unidade.

O PDBLP, antes de 1951 não faz referência a nenhum país e, posteriormente a essa data, se refere ao Brasil, enquanto o GNDLP faz referência a Portugal, apresentando progressista de duas formas diferentes: progressista enquanto adjetivo referente a um partido político; e progressista, enquanto substantivo masculino, como membro daquele partido. Desse modo, observamos que o PDBLP, a partir de 1951, ao evidenciar um lugar para o Brasil, para o povo Brasileiro, reforça o imaginário de especificidade da Língua Nacional. Sendo assim, acreditamos que é possível dizer que há um embate entre os sentidos sobre a língua que esses dois dicionários descrevem.

O próximo verbete observado nesse dicionário é progressivamente. Esse verbete não está no PDBLP e no GNDLP ele aponta como acepção "De modo progressivo; com progresso". Desse modo, são retomados os sentidos dos verbetes progressivo e progresso, que serão analisados na sequência.

Quanto às acepções observadas no verbete cuja palavra-entrada é progressivo, o GNDLP traz também algumas diferenças em relação ao PDBLP. No PDBLP esse verbete, assim como progressão, possibilitava uma ambiguidade entre "continuação" e mudança, "desenvolvimento", o que não ocorre no GNDLP, pois as acepções são separadas em conjuntos, da seguinte forma: "Que se adianta ou avança gradualmente". 2. "Que se vai realizando gradualmente". 3. "Que é cada vez maior". 4. "Que progride"; "que segue uma progressão"; "que faz progressos". Essas acepções trazidas nesse dicionário apontam para progressivo os sentidos de avanço e assim como no PDBLP, de "adiantamento em sentido favorável".

\footnotetext{
${ }^{19}$ Em relação ao imaginário de unidade da língua nacional, Orlandi (2002, p. 101 - 103) diz que a organização do discurso lexicográfico e também as "iniciativas que vão desde vocabulários, listas de palavras, dicionários bilíngues, dicionários monolíngues, porque estes, como sabemos, são parte da gramatização de uma língua e, como a gramática, representam a relação dos falantes com a língua nacional, provendo-as de uma realidade histórica e social e garantindo sua unidade (imaginária)".
} 
No PDBLP, além dessas diferenças, a partir da nona edição é apresentada também uma definição “(Med.) (V. Paralisia)”. Essa relação indica para o PDBLP um sentido de progressivo enquanto "movimento desfavorável", mas que não afeta o sentido favorável produzido para o progresso e as outras cognatas. No GNDLP não são apresentados sentidos negativos, desfavoráveis para os verbetes analisados.

$\mathrm{Na}$ sequência de verbetes está progresso, que nesse dicionário traz seis conjuntos de acepções, sendo que quatro desses conjuntos evidenciam cada um uma acepção presente no PDBLP. As acepções apresentadas no GNDLP são:

1. Marcha ou movimento para diante. 2. Desenvolvimento, continuação ou acrescentamento de um ser, de uma ação. 3. Vantagem obtida; bom êxito. 4. Adiantamento, aperfeiçoamento, melhoramento. 5. Aumento progressivo e gradual. 6. Movimento progressivo da civilização e das instituições políticas; tendência do gênero humano para a sua perfeição, para a felicidade. (FREIRE, 1942-43)

Essas acepções mantêm para progresso, especialmente, os sentidos de "adiantamento em sentido favorável" e de "transformações da vida social", indicando um movimento positivo/favorável. O sentido de progresso como "favorável" e as relações com o quadro sociológico, observados desde o PDBLP, são reforçados pelas acepções "vantagem obtida", "bom êxito", “aperfeiçoamento", "melhoramento", e também pela acepção "tendência do gênero humano para a sua perfeição, para a felicidade".

O sexto conjunto de acepções remete especificamente ao humano, ao social. Nessa medida, aponta o progresso como uma característica das "sociedades civilizadas" e que sejam dotadas de "instituições políticas"; indica também, o sentido de progresso como ligado à "perfeição" e à "felicidade", cuja busca é uma característica inerente à espécie humana, uma tendência do ser humano às virtudes. Desse modo, o sentido de progresso aponta para o discurso teleológico psicológico, pois indica um fim, uma finalidade psíquica para o progresso.

O progresso significa ainda como uma extensão, a partir do subverbete "progresso do tempo", que é definido como "o decurso ou o correr do tempo". Desse modo, o progresso do tempo é algo que ocorre naturalmente, é uma característica própria do tempo. Nesse caso, o progresso do tempo é algo que não pode ser evitado.

As análises desenvolvidas até o momento permitem observar que o Grande $e$ Novíssimo Dicionário da Língua Portuguesa aponta para a palavra progresso e suas cognatas um sentido positivo, em direção às mudanças e ao "adiantamento em sentido 
favorável", e produz também, para o verbete progredir, um sentido de rompimento com o passado, significando uma forma necessária para que a sociedade possa progredir. Essa forma apresentada altera as relações com os movimentos da sociedade apresentados até o momento.

Nesse dicionário a palavra-base é progresso, pois a maioria das palavras analisadas se concentra em torno dela, é também a palavra-eixo, pois todas as outras significam em torno somente dela. Nesta direção, nesse acontecimento, são reforçadas as relações de determinação observadas no PDBLP, em que progresso é a palavra-base em todas as edições.

\section{Dicionário da Língua Portuguêsa (1966)}

Esse dicionário (DLP), organizado por Antenor Nascentes, apresenta menos verbetes que os dicionários anteriores, cujas palavras-entrada têm a mesma raiz que progresso, somente cinco. São elas: progredir, progressão, progressista, progressivo e progresso. Em relação ao PDBLP, o DLP não apresenta a palavra progredimento; quanto ao GNDLP, não traz as palavras: progredimento, progressismo, progressivamente.

A primeira palavra-entrada deste dicionário é progredir. Ela tem apenas uma acepção: "marchar para a frente com presteza", e que retoma, de certo modo, uma das acepções observadas no PDBLP ("caminhar para diante"), exceto por expressar a forma como se deve marchar: "com presteza", o que não é exposto naquele dicionário. Desse modo, progredir, aqui no DLP, não significa apenas "marchar", mas também que essa marcha deve ser realizada de uma maneira específica. Diferente disso, o GNDLP não traz a acepção "marchar", mas apresenta, em um dos seus exemplos ("achando o caminho aberto progredira com mais rapidez" (Herculano)), uma forma específica como se pode progredir, rapidamente.

Nas definições para progredir o PDBLP traz "caminhar para diante" que tem como sentido um movimento em uma direção específica, para frente. Essa acepção estabelece uma paráfrase com a definição do PDBLP, mas à diferença deste dicionário, o PDBLP traz ainda mais definições: "avançar"; "ir aumentando"; "fazer progresso"; "evolver"; "rel. desenvolver-se"; "adiantar-se". As definições apresentadas no GNDLP, apontam para o sentido de movimento: "Ir em progresso"; "avançar", "prosseguir": "achando o caminho aberto progredira com mais rapidez" (Herculano); “deslumbrados 
com dois séculos de pacifico predomínio, adormeceram e pararam, quando fora de Portugal tudo caminhava e progredia" (Rebêlo Da Silva); "Fazer progressos"; "desenvolver-se", "adiantar-se"; "Queria-se melhorar, mas em vez de progredir, retrogradou-se" (Rebêlo Da Silva); “A vida aperfeiçoa-se e progride com a própria destruição dos antecedentes organismos" (Latino Coelho); "Ele progride nos seus estudos" (Aulete); "Ir aumentando", todas essas definições estabelecem paráfrases com as acepções apresentadas no PDBLP e no DLP.

O segundo verbete trazido pelo DLP, progressão, traz as seguintes acepções: "desenvolvimento progressivo", "progresso"; "Continuação", "sucessão". Essas acepções apontam para progressão um sentido de movimento e de desenvolvimento. Nessas relações, assim como nas do GNDLP, não ocorrem ambiguidades, como ocorre com a acepção "continuação" no PDBLP, pois aqui as acepções são separadas em conjuntos, o que permite distinguir o sentido de cada conjunto. Desse modo, as determinações para progressão, presentes no DLP, significam para "continuação" as mesmas relações de sentido, de movimento e desenvolvimento, observadas nas demais acepções.

O verbete cuja palavra-entrada é progressista apresenta uma diferença em relação aos dicionários anteriores. Nesse dicionário, progressista é "amigo do progresso". Esse sentido de amigo traz para esta acepção a significação de um discurso psicológico, que apresenta uma relação com o dicionário anterior, representando uma simpatia, uma apreciação pelo progresso. Desse modo, não se trata de uma posição como favorável, mas de um sentimento que aponta para o progresso como benéfico.

Esse dicionário apresenta para progressivo uma acepção que se difere das anteriores e faz parte do domínio da Língua Portuguesa. Considerado no que se refere à gramática, progressivo é aquele "que atua sôbre fonema seguinte (assimilação, dissimilação)". Desse modo, esta acepção apresenta um sentido de transformação, de mudança, produzido pelas alterações por que passam as palavras, em seu interior, na relação com a dinamicidade da linguagem.

No verbete progresso são observadas as acepções "marcha para frente", "desenvolvimento", “continuação", “acrescentamento de uma ação", "adiantamento", "aperfeiçoamento", "aumento gradual", "movimento de melhoria da civilização", "tendência para a perfeição, a felicidade, a riqueza, o bem-estar". Essas acepções constituem paráfrases das acepções presentes no verbete progresso trazido pelos outros 
dois dicionários analisados, o PDBLP e o GNDLP, pois mantêm os sentidos de "movimento", de "adiantamento em sentido favorável" e ainda de uma capacidade unicamente humana relacionada às "transformações na vida social" em busca de bens materiais e de virtudes humanas e sociais.

Os verbetes analisados nesse dicionário apontam para a palavra progresso e suas cognatas os mesmos sentidos de movimento, de "transformações na vida social" e de "adiantamento em sentido favorável", observados nos dicionários analisados anteriormente. Da mesma forma produzem também o sentido de movimento positivo, "favorável" para essas determinações.

Nesse dicionário as palavras-eixo são progredir e progresso e a palavra-base é progresso, o que pode estar evidenciando a posição dessa palavra como de maior aceitação e maior domínio pela sociedade, como foi evidenciado também no GNDLP e, em certo momento, no PDBLP ${ }^{20}$.

\section{Algumas considerações}

Com o desenvolvimento desta análise, espero ter contribuído para uma nova reflexão sobre a constituição dos sentidos da palavra progresso e suas cognatas na relação da língua com a sociedade. Palavras que foram observadas em três dicionários produzidos na mesma época, mas que trouxeram diferenças importantes. Essas diferenças podem ser observadas na composição textual, pela quantidade de entradas apresentadas em cada dicionário (no PDBLP são seis; no GNDLP, oito; e no DLP, cinco), e também, e principalmente, nos sentidos apresentados nas determinações dessas entradas, que, mesmo nos casos em que as entradas são semelhantes, apresentaram sentidos diferentes.

Essas relações, observadas em cada acontecimento enunciativo, apresentam sentidos que se repetem e sentidos que se deslocam, o que demonstra a produtividade das palavras na língua e os sentidos produzidos nessas relações que são enunciativas.

A observação da palavra progresso e suas cognatas nas relações com outras palavras que são apresentadas como que estabelecendo uma sinonímia, definindo-as,

\footnotetext{
20 À diferença do GNDLP e do DLP que apresentam somente uma edição, no PDBLP, que foram analisadas várias edições, foram observadas as palavras progredir e progresso como eixo, e a palavra progredir como base ao longo das primeiras edições, vindo, a partir da terceira edição, de 1942, a alterar esse domínio que, só então, passou a ter como palavra-base progresso.
} 
nos permitiu compreender o modo como ao se referir ao mesmo ele significa como diferente de si. Essas relações polissêmicas evidenciam os deslocamentos de sentido produzidos na enunciação dos dicionários analisados. Relações como as apresentadas desde a primeira edição do PDBLP em que a palavra progressão está determinada por sentidos que indicam direções distintas como permanência e continuidade, assim como progressivo que por estar determinado por progressão é afetado por suas relações.

Nessa mesma direção, a palavra progresso ao ser determinada pelo social, na terceira edição, deixa de apresentar relações somente parafrásticas, pois ocorre uma divisão de sentidos ao serem apontadas duas direções: uma de "acumulação de aquisições materiais" e outra de "transformação da vida social". Desse modo, o sentido de movimento se divide e deixa de ser único passando a apontar também o sentido de progressão que aponta para o aumento, a continuação.

O sentido do adjetivo progressista, apontado para a sociedade em geral, também se divide. Esse movimento é apresentado na edição de 1951, diante da inserção do memorável da política brasileira, no enunciado que se refere à política do Padre Feijó no período regencial, no Brasil. Esse memorável instala um sentido específico para progressista na sociedade brasileira e diferencia seus sentidos das demais sociedades.

Ao receber uma marcação do domínio da medicina, ainda na nona edição, o sentido de progressivo também é dividido, pois nesse momento é estabelecido um paradoxo, em que o progressivo passa a apontar para o favorável, na relação com o movimento, e para o desfavorável, na relação com a paralisação.

Em relação à palavra progressista, no PDBLP é a sociedade brasileira que está sendo rememorada como constituindo a história desta palavra, estabelecendo a língua do Brasil a partir da própria história e o sujeito progressista afetado por esta relação. Já no GNDLP é a sociedade portuguesa que é rememorada como parte da história daquela palavra, sendo estabelecida uma unidade entre a língua do Brasil e a de Portugal. Nessas relações o sujeito progressista é afetado pelos sentidos constituídos no país colonizador. Desse modo, as alterações nas relações entre essas palavras produzem para elas novos sentidos que são afetados a partir das alterações nas relações da sociedade.

Foi muito importante observar os movimentos da palavra progresso e suas cognatas nesses dicionários, pois trouxe a possibilidade de visualizar alguns movimentos da sociedade brasileira em um momento em que os primeiros dicionários brasileiros estavam sendo elaborados, a partir de 1939 e nas décadas subsequentes. 
Desse modo, esses dicionários apresentaram relações que produziram sentidos em torno de mudança, movimento, e "adiantamento em sentido favorável". Sentidos que vão sendo reforçados ou alterados ao longo das edições do PDBLP e ainda na comparação com os outros dois dicionários: GNDLP e DLP, inclusive na apresentação de um quadro sociológico em que aparece, de modos diferentes, as relações com o cultural, com a civilização e com valores.

No que se refere às alterações, uma questão bastante interessante que ocorre no PDBLP é a mudança de posição entre as palavras progresso e progredir que são palavras-eixo nas relações analisadas e, em momentos distintos, cada uma ocupa o lugar de palavra-base nessas relações. Na primeira edição a palavra que é a base para a relação entre as cognatas é progredir, relação que é alterada, e, na terceira edição, a posição de palavra-base é ocupada por progresso. Essas relações indicam qual das palavras está em evidência, é mais conhecida, tem maior aprovação e ganha força na sociedade. Sendo assim, o PDBLP mostra que a partir de 1942, é a palavra progresso que ocupa essa posição de destaque e de maior aprovação pela sociedade, posição que é apresentada também no GNDLP e no DLP.

Esses sentidos de progresso enquanto palavras-base apresenta uma proximidade com as relações observadas para a palavra progresso na enunciação que se refere ao movimento político da marcha para o Oeste estabelecido pelo Presidente Getúlio Vargas. Nessas relações, analisadas em alguns textos publicados no jornal "O Estado de Mato Grosso", a palavra progresso ocupa uma posição de destaque e funciona como sendo conhecida e importante para a sociedade, e como se seu sentido fosse evidente, por isso não são apresentadas definições. Esta palavra é ainda repetida muitas vezes, como se fosse um slogan ressaltando que "é preciso progresso".

Outro movimento muito importante que foi observado nos três dicionários, mas de modo diferente, é a relação entre a palavra progresso e o social. Sendo que no PDBLP o progresso é determinado, no que se refere ao social, na relação com bens materiais, com cultura, com vida social; no GNDLP o progresso está relacionado com as sociedades civilizadas, sendo uma característica dessas sociedades a busca pela perfeição e a felicidade, assim o progresso aponta para uma finalidade; no DLP o progresso é apontado como um movimento que é próprio da civilização e que, assim como no GNDLP, tem uma finalidade psíquica e que é própria da civilização: a busca pelos valores. Essas relações estão presentes na enunciação do jornal analisado, podendo ser observadas, por exemplo, nas contiguidades entre o progresso e a 
civilização, a cultura, os bens materiais, apontando sempre para uma finalidade: a evolução humana e o bem-estar. Desse modo, o progresso mantém um movimento geral na direção do favorável, do positivo.

\section{Referências Bibliográficas}

AUROUX, Sylvain. A revolução tecnológica da gramatização. Tradução Eni Orlandi, Campinas, SP: Editora da Unicamp, 1992.

GUIMARÃES, Eduardo. Texto e argumentação: um estudo de conjunções do português. 3. Ed. Campinas, SP: Pontes, 2002.

. Semântica do Acontecimento: um estudo enunciativo da designação. Campinas, SP: Pontes, 2002.

Pontes, 2004.

História da semântica: sujeito, sentido e gramática no Brasil. Campinas, SP:

Civilização na Lingüística brasileira no século XX. In: Matraga. Rio de Janeiro: UERJ, 2004a.

Os Limites do sentido: um estudo histórico enuncativo da linguagem. 3. ed. Campinas, SP: Pontes, 2005.

RG, 2011.

Análise de texto: Procedimentos, Análises, Ensino. Campinas, SP: Editora

HORTA NUNES, José. Dicionário, ciência e desenvolvimento nos tempos JK. (in.) MARIANI, Bethania; MEDEIROS, Vanise (orgs.) Ideias Linguísticas: formulação e circulação no período JK. Rio de Janeiro, Faperj - Campinas: Editora RG, 2010.

MACHADO, Carolina de Paula. A designação da palavra preconceito em dicionários atuais. 2007. 134p. (Tese Mestrado em Linguística) - Instituto de Estudos da Linguagem. Universidade Estadual de Campinas, Campinas, 2007.

ELIAS DE OLIVEIRA, Sheila. Cidadania: história e política de uma palavra. Campinas: Pontes Editores, RG Editores, 2006.

Cidade e urbanidade: algumas relações entre palavras. Web revista discursividade: estudos linguísticos, $\mathrm{n}^{\circ}$. 6, Campo Grande, 09 de janeiro de 2012. Disponível em <http://www.cepad.net.br/discursividade/>. Acesso em 05 de maio de 2012.

OLIVEIRA, Rosimar Regina Rodrigues de. O Progresso na "Marcha para o Oeste": Uma Análise Enunciativa na Imprensa Mato-grossense. 116p. (Dissertação de Mestrado em Linguística) - Instituto de Estudos da Linguagem. Universidade Estadual de Campinas, Campinas, 2007. 
Alguns sentidos de modernidade. Web revista página de debates: questões de linguística e linguagem. $\mathrm{n}^{\circ}$ 10, Nova Andradina, outubro de 2009. Disponível em: <http://www.cepad.net.br/linguisticaelinguagem/EDICOES/10/10.htm> Acesso em abril de 2012.

O Estado de Mato Grosso e a modernidade no discurso de Dante de Oliveira. Web revista página de debates: questões de linguística e linguagem. $\mathrm{n}^{\circ} 11$, Nova Andradina, novembro de 2009 (2009a). Disponível em: $<$ http://www.cepad.net.br/linguisticaelinguagem/EDICOES/11/11.htm $>$ Acesso em abril de 2012.

ORLANDI, Eni Puccinelli. Um sentido positivo para o cidadão brasileiro. In: ORLANDI, Eni Puccinelli; LAJOLO, Marisa; IANNI, Otávio. Sociedade e linguagem. Campinas, SP: Editora da UNICAMP, 1997.

Pontes, Análise do discurso: princípios e procedimentos. 2. ed. Campinas - SP: 2000.

2001 .

Apresentação. In. História das idéias lingüísticas. Campinas - SP: Pontes, Língua e conhecimento linguístico: para uma história das ideias no Brasil. São Paulo: Cortez, 2002.

\section{Referência dos Dicionários}

MORAES SILVA, ANTONIO DE. Diccionário da Língua Portugueza Recopilado Typographia Lacerdina, Lisboa, 1813.

LIMA, HILDEBRANDO DE e BARROSO, GUSTAVO (Orgs.). Pequeno Dicionário Brasileiro Da Língua Portuguesa (1, 2, 3, 5, 6, 9, 10, 11. Eds.). Civilização Brasileira, Rio de Janeiro, 1938.

FREIRE, LAUDELINO (org.). Grande e Novíssimo Dicionário da Língua Portuguesa. Vol. IV A noite Editora, Rio de Janeiro, 1942-43.

NASCENTES, ANTENOR. (Academia Brasileira de Letras), Dicionário da Língua Portuguêsa. Departamento de Imprensa Nacional, 1966.

NASCENTES, ANTENOR. Dicionário Etimológico Resumido (Coleção dicionários Especializados - 1). Instituto Nacional do Livro. Ministério da Educação e culturra, 1966. 


\section{ANEXO}

O Pequeno Dicionário - primeira e segunda edições (1938 - 1939)

Progredimento, n. m. Ato ou efeito de.

Progredir, v. int. Caminhar para diante; avançar; desenvolver-se; ir aumentando.

Progressão, $n$. f. Progredimento; continuação; (matem.) série de números ou têrmos entre cada um dos quais e o antecedente há uma razão constante.

Progressista, adj. Partidário do progresso; que é favorável ao progresso.

Progressivo, adj. Que progride; que muda de lugar, andando; que segue uma progressão; que se vai realizando gradualmente.

Progresso, n. m. Movimento ou marcha para a frente; desenvolvimento; aumento; adiantamento em sentido favorável.

\section{O Pequeno Dicionário - terceira e quinta edições (1942 - 1944)}

Progredimento, s. $m$. Ato ou efeito de

Progredir, v. int. Caminhar para diante; avançar; ir aumentando; fazer progresso; evolver; rel. desenvolver-se; adiantar-se.

Progressão, s. f. Progredimento; continuação; (Mat.) série de números ou termos entre cada um dos quais e o antecedente há uma razão constante; a progressão diz-se aritmética ou geométrica segundo a razão (constante) é por diferença ou por quociente.

Progressista, adj. Partidário do progresso; que é favorável ao progresso.

Progressivo, adj. Que progride; que muda de lugar, andando; que segue uma progressão; que se vai realizando gradualmente.

Progresso, s. m. Movimento ou marcha para a frente; desenvolvimento; aumento; adiantamento em sentido favorável; (sociol.) acumulação de aquisições materiais e de conhecimentos objetivos no quadro de uma cultura; fenômeno que tem como condição as transformações da vida social, e consiste num aumento de significado e alcance da experiencia humana.

O Pequeno Dicionário - sexta, nona, décima e décima primeira edições (1946 - 1951 - 1963 - 1968)

Progredimento, s. $m$. Ato ou efeito de

Progredir, v. int. Caminhar para diante; avançar; ir aumentando; fazer progresso; evolver; rel. desenvolver-se; adiantar-se. (Irregular. Conjuga-se como o verbo agredir.)

Progressão, s. f. Progredimento; continuação; (Mat.) série de números ou termos entre cada um dos quais e o antecedente há uma razão constante; a progressão diz-se aritmética ou geométrica segundo a razão (constante) é por diferença ou por quociente.

Progressista, adj. 2 gên. e $s .2$ gên. Que, ou pessoa que é favorável ao progresso; partidário do progresso; (Bras.) partidário da Regência do Padre Feijó.

Progressivo, adj. Que progride; que muda de lugar, andando; que segue uma progressão; que se vai realizando gradualmente; (Med.) (V. Paralisia).

Progresso, s. m. Movimento ou marcha para a frente; desenvolvimento; aumento; adiantamento em sentido favorável; (Sociol.) acumulação de aquisições materiais e de conhecimentos objetivos no quadro de uma cultura; fenômeno que tem como condição as transformações da vida social, e consiste num aumento de significado e alcance da experiência humana.

\section{Grande e Novíssimo Dicionário da Língua Portuguesa}

PROGREDIMENTO, s. m. De progredir + mento. Ato ou efeito de progredir.

PROGREDIR, v. r. v. Lat. progredi. Ir em progresso; avançar, prosseguir (intr.; tr. ind., com prep. com): "achando o caminho aberto progredira com mais rapidez" (Herculano). "deslumbrados com dois séculos de pacifico predomínio, adormeceram e pararam, quando fora de Portugal tudo caminhava e progredia" 
(Rebêlo da Silva). "A vida aperfeiçoa-se e progride com a própria destruição dos antecedentes organismos" (Latino Coelho). I| 2. Fazer progressos; desenvolver-se, adiantar-se (intr.; tr. ind., com prep. em): "Queria-se melhorar, mas em vez de progredir, retrogradou-se" (Rebêlo da Silva). "Ele progride nos seus estudos" (Aulete). $\|$ 3. Ir aumentando (intr.).

PROGRESSÃO, s. f. Lat. progressio; progressionem. Desenvolvimento progressivo; progresso. \|I 2. Continuação, sucessão. \| 3. Marcha ou movimento para diante. || 4. Mat. Série de números que derivam sucessivamente uns dos outros segundo uma mesma lei.

PROGRESSÃO ARITMÉTICA, s. f. Mat. Série de números, cada um dos quais é igual ao precedente, aumentado ou diminuído de certa quantidade constante, chamada razão.

PROGRESSÃO ASCENDENTE, s. f. Mat. Aquela cujos termos são cada vez maiores.

PROGRESSÃO DESCENDENTE, s. f. Mat. Progressão cujos termos vão decrescendo.

PROGRESSÃO GEOMÉTRICA, s. f. Mat. Série de números, cada um dos quais é igual ao precedente, multiplicado ou dividido por uma quantidade constante, chamada razão.

PROGRESSÃO POR DIFERENÇA, s. f. O mesmo que progressão aritmética.

PROGRESSÃO POR QUOCIENTE, s. f. O mesmo que progressão geométrica.

PROGRESSISMO, s. m. Tendência progressista.

PROGRESSISTA, adj. Relativo ao progresso ou a progressistas. II 2. Partidário do progresso; que é favorável ao progresso. $\|$ 3. Diz-se de um partido político em Portugal.

PROGRESSISTA, s. m. Partidário das ideias do progresso. $\| \underline{2 .}$ Membro de um partido político, que em Portugal se denominou progressista.

PROGRESSIVAMENTE, adv. De progressivo + mente. De modo progressivo; com progresso.

PROGRESSIVO, adj. De progresso + ivo. Que se adianta ou avança gradualmente. \| 2. Que se vai

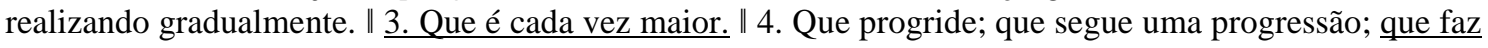
progressos.

PROGRESSO, s. m. Lat. progressus. Marcha ou movimento para diante. \|I 2. Desenvolvimento, continuação ou acrescentamento de um ser, de uma ação. \| 3. Vantagem obtida; bom êxito. $\| 4$. Adiantamento, aperfeiçoamento, melhoramento. \| 5. Aumento progressivo e gradual. \|6. Movimento progressivo da civilização e das instituições políticas; tendência do gênero humano para a sua perfeição, para a felicidade.

PROGRESSO DO TEMPO, s. m. O decurso ou o correr do tempo.

\section{Dicionário da Língua Portuguêsa}

progredir. (progri'di..) V. intr. Marchar para a frente com presteza. (Do lat. *progredere por progredi).

progressão. (progre'sãŭ) S F. Desenvolvimento progressivo, progresso. Continuação, sucessão. Série de quantidades que crescem ou decrescem segundo uma lei. $\|$ - por diferença, aquela em que um têrmo é igual ao antecedente ou ao subseqüente menos a razão. $\|$ - por quociente, aquela em que um têrmo é igual ao antecedente ou ao consequiente dividido pela razão. (Do lat. progressione)

progressista. (progre'sišta) Adj. Amigo do progresso. || U.t.c.s. Pessoa progressista.

progressivo, a. (progre'sivu, a) Adj. Que progride gradualmente, que aumenta cada vez mais, que faz progresso. \| (Gram.) Que atua sôbre fonema seguinte (assimilação, dissimilação).

progresso. (pro'gresu) S. masc. Marcha para frente. Desenvolvimento, continuação, acrescentamento de uma ação. Adiantamento, aperfeiçoamento. Aumento gradual. Movimento de melhoria da civilização, tendência para a perfeição, a felicidade, a riqueza, o bem-estar. (Do lat. progressu). 


\title{
Revista do Laboratório de
}

Estudos Urbanos do Núcleo

de Desenvolvimento da Criatividade

Para citar essa obra:

DE OLIVEIRA, Rosimar Regina. O "progresso" e a significação da sociedade em alguns dos primeiros dicionários monolíngues brasileiros. RUA [online]. 2013, no. 19. Volume 1 - ISSN 1413-2109

Consultada no Portal Labeurb - Revista do Laboratório de Estudos Urbanos do Núcleo de Desenvolvimento da Criatividade

http://www.labeurb.unicamp.br/rua/

Capa. ABRÃO, Jorge. 2013. Progresso. Fotografia, color, $38 \mathrm{~cm}$ x $28 \mathrm{~cm}$.

\author{
Laboratório de Estudos Urbanos - LABEURB \\ Núcleo de Desenvolvimento da Criatividade - NUDECRI \\ Universidade Estadual de Campinas - UNICAMP \\ http://www.labeurb.unicamp.br/ \\ Endereço: \\ LABEURB - LABORATÓRIO DE ESTUDOS URBANOS \\ UNICAMP/COCEN / NUDECRI \\ CAIXA POSTAL 6166 \\ Campinas/SP - Brasil \\ CEP 13083-892 \\ Fone/ Fax: (19) 3521-7900 \\ Contato: http://www.labeurb.unicamp.br/contato
}

